\title{
Supporting Graduate Student Scholarly Writing Growth: Learner Perspectives on the Tasks Ahead
}

\author{
Barbara D. Holmes \\ Leadership Education Department, Winona State University, Winona, MN, USA \\ Email: bholmes@winona.edu
}

How to cite this paper: Holmes, B. D. (2022). Supporting Graduate Student Scholarly Writing Growth: Learner Perspectives on the Tasks Ahead. Open Journal of Leadership, 11, 13-18.

https://doi.org/10.4236/ojl.2022.111002

Received: October 21, 2021

Accepted: February 25, 2022

Published: February 28, 2022

Copyright $\odot 2022$ by author(s) and Scientific Research Publishing Inc. This work is licensed under the Creative Commons Attribution International License (CC BY 4.0).

http://creativecommons.org/licenses/by/4.0/ (c) (i) Open Access

\begin{abstract}
This qualitative study explores academic writing experiences of graduate students enrolled in a Master of Organizational Leadership Education program. Participatory action research method was employed to connect with students and gain insight into writing anxiety and barriers to the development of scholarly identity. Four emergent themes describe participant experiences associated with addressing writing concerns and anxieties: 1) Scholarly writing challenges are not delimited by age, gender, or professional experience, 2) The shift from informal writing to formal writing is cumbersome, 3) Academic writing negatively affected self-efficacy, and 4) Organizing the manuscript narrative presented the most difficult challenge. Feedback from graduate students tasked with academic writing indicates that academic writing instruction should start earlier in instructional programs and faculty should work as writing partners with emergent academic writers. Implications: Graduate preparation programs should emphasize the critical importance of academic writing development for successful matriculation in advanced study.
\end{abstract}

\section{Keywords}

Academic Writing Development, Scholarly Identity, Organizational Leadership Development, Graduate Student Writing

\section{Graduate Student Writing Challenges}

A growing number of graduate students continue to struggle with the mastery of 
scholarly writing. To gain insight into this phenomenon, graduate students in a scholarship and research class were surveyed to obtain perspectives on what is needed to improve writing outcomes. Graduate students report that writing instruction should start earlier in the curriculum and more opportunities to write scholarly papers and narratives are needed. Holmes et al. (2018) discovered that graduate students struggle with a real fear of committing thoughts and ideas to writing in a scholarly environment. It is important for graduate faculty to gain better understanding of the strategies and practices that hold potential to support graduate students who are struggling with negative feelings about writing.

This study was situated in a graduate class in which students were required to demonstrate writing proficiency through the production of a research prospectus and a review of the supporting research literature. As draft assignments were turned in, it became obvious that students were challenged to develop effective thesis sentences, develop and sustain an academic argument, write in active rather than passive voice and use economy of expression to convey main ideas and thoughts. Students presented narratives that were unorganized and failed to logically justify the claims and assertions in the manuscript.

\section{Problem Background}

Graduate student anxiety about academic writing was exacerbated during the pandemic. Students had no physical proximity to the instructor or fellow students and felt very isolated in the struggle to write. Fernandes (2021) summarized that graduate students exhibited high anxiety across a variety of factors during the pandemic. Woolston (2020) explained that in addition to the regular stress of graduate study, students were required to manage work-life balance issues, mental health struggles, and the challenges associated with participating in online instruction. These issues were compounded by the need to master academic writing and research issues at the same time. Not only were these difficult times for students, but Troop (2021) cautioned that it was also a difficult time for faculty members trying to support student learning in a high stakes arena of producing original research. Many of the students enrolled in the scholarship and research class were in the last year of the program of study and were anticipating face-to-face interviews with identified participants. During the pandemic, it became challenging to schedule interviews and many students had to revise the proposed research design and methodology. These unanticipated problems in many instances were difficult to overcome.

June (2021) summarized that the global pandemic put a strain on university students across the nation. Challenges faced by students were unprecedented during the pandemic and affected a myriad of issues from work life balance to worrying about meeting the expectations of academic life.

Challenges faced during the pandemic: summary of students' responses 


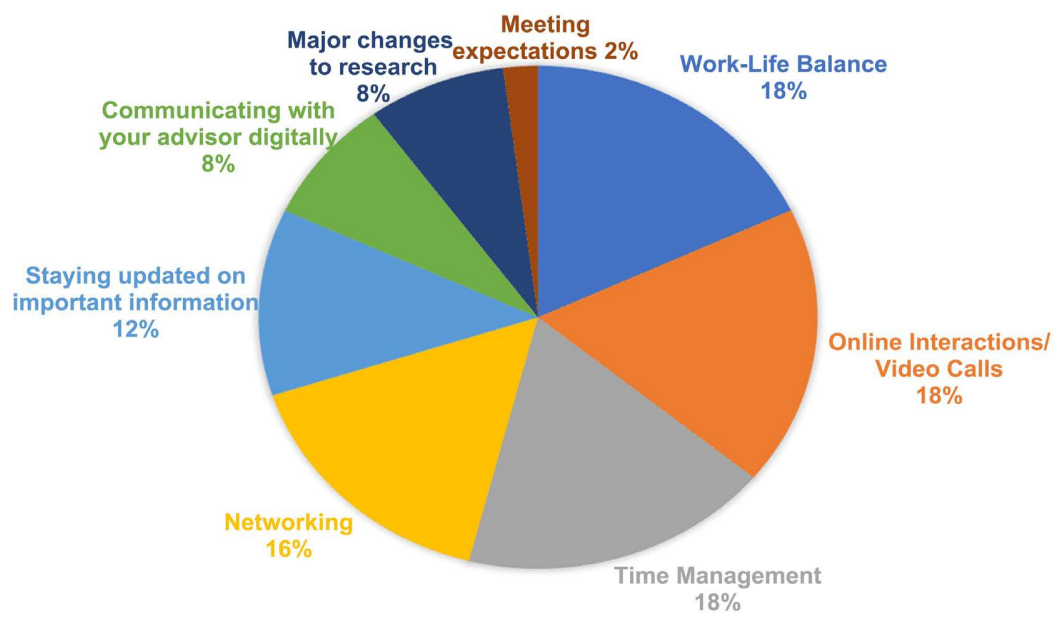

Source: https://spsp.org/news-center/announcements/graduate-students-impact-of-pandemic

\section{Method}

At the midpoint period of the class, students were asked to participate in an action research project to help provide feedback on writing struggles and to help the instructor make instructional adjustments in the class. Bair and Mader (2013) advised that graduate programs "cannot leave the development of graduate writing to chance...it needs to be infused into the curriculum, introduced early and revisited in more complex ways" (p. 10).

The instructor used an action research protocol to gather participant responses in this inquiry. Through the action research process, instructors may gather information from learners that illuminates understanding of what is happening in the classroom and identify changes with potential to improve teaching and learning. Action research results help answer questions about the effectiveness of specific instructional strategies used in academic writing development and the learning needs of specific students. The instructor administered a ten-question survey to enrolled students and held a focus group discussion related to the results of the survey.

\section{Results}

Graduate students completing the survey $(\mathrm{N}=9)$ were all enrolled in the scholarship and research class and had completed all program courses in the Organizational Leadership Master's program except for the capstone course that all will take next semester. The survey consisted of ten questions with three questions specifically focused on academic writing:

1) What is your opinion of academic writing?

2) What is the most challenging aspect of academic writing for you?

3) What is the most important thing you can do to grow as an academic writer?

Students reported that academic writing was challenging, difficult to understand and master and consumes a lot of time. The most challenging aspect of academic writing included time on task, learning to write with economy of expression with $74 \%$ of respondents reporting having difficulty with organizing the written narr- 
ative. In terms of growing as academic writers, participants (67\%) reported needing to see more specific exemplars of academic writing with $23 \%$ advocating for more time to practice academic writing. The majority of participants (75\%) indicated that more exposure to exemplars of previously approved capstones and theses was extremely helpful in shaping academic writing strength.

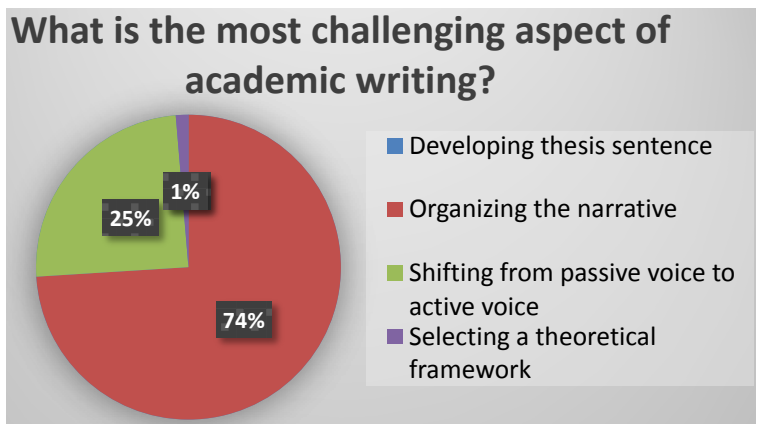

During the class focus group, respondents welcomed the opportunity to discuss writing challenges openly with the goal of writing improvement. All students agreed that earlier exposure to the conventions of academic writing at the beginning of the program of study would have been extremely critical in writing development. One student expressed that the writing struggles "were forcing me to rethink whether I really want a master's degree." One student majoring in Sports Management indicated that he had talked to several students who completed the class last year and "all of them were surprised by the emphasis on academic writing and none were prepared for it".

After an hour of discussion, students were asked to identify the common themes expressed in the focus group about academic writing and what strategies might be helpful to them in improving scholarly writing.

The discussion yielded four emergent themes:

Emergent Theme 1: Scholarly writing challenges are not delimited by age, gender, or professional experience

The class was composed of students with varying levels of professional experience, administrative authority, coaches, admissions counselors, and school administrators. All expressed frustration with writing in scholarly conventions and exhibited enormous frustration with the task. Some respondents were constrained by time management issues, job priorities and mental health issues in trying to cope with the impact of the pandemic on ordinary life. In essence, this was a difficult time to learn a new skill known as scholarly writing. Participants reported that more time needs to be embedded in instruction to work on scholarly writing.

Emergent Theme 2: The shift from informal writing to formal writing is cumbersome

Graduate students in the class all write informally daily in communications with various stakeholders. The use of informal language is practiced regularly and is a part of normal operational activities. In daily job responsibilities, par- 
ticipants viewed themselves as accomplished and proficient writers. Having to shift from informal writing to technical objective writing was unwieldy and tedious. Students were not able to "see" the academic writing errors until they were pointed out by reviewers of the writing. Personal proofreading and editing did not inform writing mistakes and errors. It should be recognized that high stakes writing assignments may be stress-inducing to students unfamiliar with this style of writing.

Emergent Theme 3: Academic writing negatively affected self-efficacy

Despite being highly accomplished in other aspects of academic progress, respondents reported a signal lack of confidence in scholarly writing confidence. Plakhotnik and Rocco (2015) concluded that students have extreme difficulty responding to the rhetorical demands of different types of writing and this affects emotion, cognition and metacognition. Students lack of self-efficacy caused them to shy away from writing assignments and offer excuses for not producing high-level writing narratives. Huerta et al. (2017) further explained that intrapersonal variables affect individuals' academic writing such as writing anxiety, self-efficacy, and emotional intelligence.

Emergent Theme 4: Organizing the manuscript narrative presented a dif-

\section{ficult challenge}

Graduate students reported that organizing the written narrative gave them the most difficulty. Students appeared to lack knowledge on how to support thesis sentences, grab the reader's attention or structure an organizer for the paper. It was difficult for the reader to preview the academic arguments and understand the main ideas the authors were attempting to structure and convey.

\section{Discussion}

To move the discussion forward, the instructor asked students what could be done to provide more support or modify instruction. Several suggestions emerged for consideration:

1) Instructors need to provide more specific embedded feedback on reviewed work. Students want to see suggested rewording on documents and highlighted areas where specific writing infractions occurred.

2) Students want class time to review more exemplars of good writing with a walkthrough of what specific components make the writing good.

3) A suggestion was made to include "workshopping" examples of writing narratives and discuss openly how to structure the narrative in a logical sequential fashion.

4) Students liked the idea of scaffolding from low stakes writing to high stakes writing to get comfortable with the writing journey. Build in writing assignments that assure writing success such as having students develop a one-page written autobiography at the beginning of the course. In this way, students get to write about themselves and promote their individual experiences and expertise.

5) Students want the instructor to commit to being a writing partner and offer 
active support when writing roadblocks are encountered.

\section{Conflicts of Interest}

The author declares no conflicts of interest regarding the publication of this paper.

\section{References}

Bair, M. A., \& Mader, C. E. (2013). Academic Writing at the Graduate Level: Improving the Curriculum through Faculty Collaboration. Journal of University Teaching and Learning Practice, 10, 16. https://doi.org/10.53761/1.10.1.4

Fernandes, S. (2021). How Has the Pandemic Affected Graduate Students? Society for Personality and Social Psychology.

https://spsp.org/news-center/announcements/graduate-students-impact-of-pandemic

Holmes, B., Waterbury, T., Baltrinic, E., \& Davis, A. (2018). Angst about Academic Writing: Graduate Students at The Brink. Contemporary Issues in Education Research (CIER), 11, 67-72. https://doi.org/10.19030/cier.v11i2.10149

Huerta, M., Goodson, P., Beigi, M., \& Chlup, D. (2017). Graduate Students as Academic Writers: Writing Anxiety, Self-Efficacy, and Emotional Intelligence. Higher Education Research \& Development, 36, 716-729. https://doi.org/10.1080/07294360.2016.1238881

June, A. W. (2021, January 26). How the Pandemic Put More Strain on Students Last Fall. The Chronicle of Higher Education.

https://www.chronicle.com/article/how-the-pandemic-put-more-strain-on-students-la st-fall

Plakhotnik, M., \& Rocco, T. (2015). Increasing Writing Self-Efficacy of Adult Learners: Different Approaches, Different Results. Adult Learning, 27, No. 5.

https://doi.org/10.1177/1045159515611879

Troop, D. (2021, March 7). "Zoom Fatigue”, Gratitude, and Purring Cats: A Peek at Life during the Pandemic. The Chronicle of Higher Education.

https://www.chronicle.com/pandemic

Woolston, C. (2020). Signs of Depression and Anxiety Soar among U.S. Graduate Students during Pandemic. Nature, 585, 147-148.

https://doi.org/10.1038/d41586-020-02439-6 